\title{
Working Hazards as Indicator of Occupational Stress of Industrial Workers of Bangladesh
}

\author{
Shayama Akhtar ${ }^{1}$, Asheek Mohammad Shimul ${ }^{2}$ \\ ${ }^{1}$ Department of Business Administration, Northern University Bangladesh, Bangladesh \\ ${ }^{2}$ Department of Psychology, University of Dhaka, Bangladesh
}

\begin{abstract}
The primary objective of the present study was to find out the hazardous factors and to see whether those factors are responsible for uplifting occupational stress in two industrial sectors of Bangladesh. And the secondary objective was to see how far the Bangladeshi industries implement the policies and rules set by Bangladesh Labor Code, 2006. To serve the above mentioned objectives two types of industries were selected purposively and following incidental sampling procedure 130 industrial workers from tannery and garments were interviewed by a structured questionnaire. Through interviewing at first the hazardous factors were identified according to the severity of effect on their physical and psychological health. Then occupational stress was identified through a questionnaire (Bangla version of Akhter, 2008) and collected data were analyzed by independent sample t-test. Results revealed that some of the hazardous factors had significant differential effects on occupational stress. This study also revealed that these two types of industries do not ensure the set working conditions with all safety and hygienic arrangements according to "The Bangladesh Labor Code, 2006".
\end{abstract}

Key Words: Working condition, occupational stress, hazardous factors JEL Classification Code: L800

\section{INTRODUCTION}

A hazard may be defined as anything with the potential to harm life, health or property (University of Manchester, Centre for Occupational and Environmental Health, 2007). In this context, hazard identification is the process of determining the hazards associated with the working environment and/or the way in which the work is done. For example, violence in the workplace by clients might be identified as a hazard.

One of the important aspects of industrial safety programs is the identification of hazards. Industrial health hazards are typically categorized into three classes: chemical hazards, in which the body absorbs toxins; ergonomic hazards, such as those resulting from improper lifting or repetitive stress; and physical hazards, in which the worker is exposed to temperature extremes, atmospheric pressure, dangerous conditions, or excessive noise (Catholic University at Lauvain, 2001).

The Health and Safety Executive surveyed of workers in New Delhi 2005 listed the most common hazards in working condition: physical (noise, vibration, heat, cold, pressure, radiation, dust, fibers), chemical (flammable/explosive materials, toxics, sensitizing agents), biological(dust, pathogens), psychological ( workplace practices \& systems, payment systems), new technologies (information \& telecommunications techs., industrial /manufacturing processes), occupational injuries \& diseases (back, RSI, skin, heart, cancer, reproductive/birth, substance abuse) etc.

Occupational stress is a major issue in today's workplace and a matter of increasing concern to employers, em- ployees, governments, insurers and the community. In some situations, people are distressed to the extent that they may be diagnosed as suffering from a range of disorders including anxiety, depression and other stressrelated conditions (World Health Assembly, 1996).

Occupational stress is a term used to define ongoing stress that is related to the workplace. The stress may have to do with the responsibilities associated with the work itself, or be caused by conditions that are based in the corporate culture or personality conflicts. As with other forms of tension, occupation stress can eventually affect both physical and emotional well being if not managed effectively.

Recent research of ILO and WHO demonstrated that occupational stress indicates that there is a range of related variables which define 'stressful' work. In summary, stressful work is characterized by high levels of job demand (work load), low levels of job control (decision making latitude), high levels of task uncertainty (technical knowledge and skill), and low organizational support (personal recognition and reward).

There is a number of working conditions that workers encounter on a daily basis which contribute to making work stressful. These working conditions are called "stressors" and consist of those things which have a negative effect on a worker's physical or emotional wellbeing, which stressors are associated with two job characteristics: job control(lack of control over work, lack of recognition for work done, job insecurity, fear of layoffs, harassment, lack of respect from supervi- 
sors, racism, sexism, age discrimination, inadequate pay, isolation from fellow employees either physically or psychologically, and lack of promotion opportunities) and Job demand(contracting out work, fragmentation/job declassification, poor ventilation and heating, poor lighting, forced overtime, shift-work, speedups, conflicting job demands, physical danger, fear of accident or even death on the job, poor computer workstation design, monitoring, lack of training, and unnecessary paperwork) (Communications Workers of America, 2005).

From the point of view of human factors, Ellis and Chandola, 2008 told about eleven occupational stressors(job security, workload, control, scheduling, job content, social environment, physical environment, relationships, role definition and feedback, change management, opportunity for learning and development) which can lead to increased absenteeism, workers compensation claims, injury frequency rates, staff turnover rates, etc.

In Bangladesh, Society for Environment and Human Development (SEHD), a Dhaka-based nongovernmental organization conducted a survey on tannery workers where it was found that there are about 270 registered tanneries and 90 percent of these are located at Hazaribag on about 25 hectares of land. Most of these are none or semi-mechanized units and these tanneries use old processing methods. During the peak period about 15,000 laborers work daily in these tanneries. The number goes down to $8,000-12,000$ during lean period. Among these workers only 30 percent wear shoes at work-place, only 3 percent wear aprons, only 3 percent wear masks and only 12 percent wear gloves. Moreover, the workers wash their hands and feet with plain water. Such results showed that about 894 workers per thousand suffer from diseases while the national level ratio was 150.85 per thousand which revealed the unplanned work environment for the tannery workers that lead them to work dissatisfaction. The SEHD also demonstrated that about 90 percent tannery workers of Bangladesh die before they reach the age of 50 due to unhygienic working-environment. About 58.10 percent of workers suffer from ulcer, 31.28 percent have skin diseases, 16.76 percent suffer from malnutrition, 11.73 percent have high blood pressure and 10.61 percent suffer from rheumatic fever, 34.63 percent of the surveyed tannery workers occasionally suffer from fever, 22.90 percent from cough and 18.99 percent from jaundice. The tannery workers complained of suffering from dizziness, headache, weakness, eye problems, abdominal pain, nausea, diarrhea, allergy, burning sensation in the chest, throat, palm and toes, urinary problems and pain in the body, waist, legs, back, throat, neck, shoulder and ankles.

In case of maintaining the healthy and safe working conditions there are some laws in Bangladesh which are followed by the reference of ILO and WHO. These rules are revised in many times and now the established one is known as "Bangladesh Labor Code, 2006". On the basis of this labor code, laws which are described as "Health and Hygiene" is in Chapter 5 and "Safety" is in Chapter 6 from the pages: 68-90. In a brief of these codes cover the following conditions as health and hygiene issue: cleanliness, ventilation and temperature, dust and fume, disposal of wastes, artificial humidification, overcrowding, lighting, drinking water, latrines, spittoons, etc. On the same time the safety issues include: safety of building and machinery, precautions in case of fire, fencing of machinery, work on or near machinery in motion.

According to this labor code, working conditions, including safety standards, in garment factories are notoriously bad in Bangladesh. Since 1990, 22 factory fires took the lives of nearly 300 garment workers and injured more than 2,500 (World Bank statistics June 2000). In garments factory, locked exits, a lack of properly functioning fire safety equipments, such as alarms, extinguishers and sprinkler systems, are common among garment factories. Too often, the factory gates were locked even though the worker exits in factory.

Recent tragedies include a fire in a garment factory near Dhaka in January 2011, which killed at least 22 workers. Last May 2010, seven people died in a stampede following a false fire alarm. In November 2000, at least 48 workers died and more than 150 were injured when they were trapped behind a locked fire exit of a burning factory.

The worst industrial accident in Bangladesh's history happened in the early hours of April 2011. This year when a nine-storey factory collapsed and ended the lives of 149 garment workers, who were performing nightshift duties at a factory of Spectrum Sweater Industries Ltd. in Palashbari, located some $30 \mathrm{~km}$ off the city of Dhaka. Fire incidents have killed more than 350 workers since 1990. A factory collapse killed 60 workers in 2005 here unaccounted for other non-fatal injuries-falls, machinery related, struck by/against, cutting \& piercing, etc. Musarrat (2001) found the following hazards in the Garments Industry of Bangladesh: crowded conditions, exposed operating machines, electrical connections are crude and unsafe, a few or no fire extinguishersinaccessible or malfunctioning, no fire practice is ever performed, managers and workers are not trained to understand health and safety issues, stairs and floors used as storage; gates remain closed even in emergency; factory not designed as commercial facility, narrow aisles for firefighters to enter and rescue. In a survey it was revealed that most garment factories of Bangladesh were often dimly lit and poorly ventilated. However, they remained in operation for long hours and the workers worked almost without any break during their shifts ( $\mathrm{Lu}$ Laizhen, 2005).

The success of any effort to minimize stress and maximize job satisfaction and performance efficiency depends upon accurate diagnosis of the potential sources of stress at work. Identification of the possible sources of stress, therefore, demands serious attention to provide those better occupational health conditions or industrial mental health (Murrell, 1978).

Actually during a long time our industrial workers both in tannery and garments, are working under an unhygie- 
nic, threatening working condition that gradually cause some violation in our industrial sectors from last several years. Despite the tremendous costs to both the individual and organizations, the problems of stress of industrial workers have been extensively studied in western industrialized countries but not much in the developing countries, like Bangladesh. There remains limited research in the industrial area of Bangladesh that comprehensively measure the prevalence and causes of stress in today's workplace. The proposed study was sought to determine some of the pertinent hazardous factors that can best predict the occupational stress within the workforce and to examine the present working condition of garment and tannery industry of Bangladesh according to "The Bangladesh Labor Code, 2006".

\section{Methods}

\subsection{Sample}

By following the cross-sectional survey design the sample was selected at one-point in time. The sample of the present study comprised of 130 nationalized industrial workers. All of the workers were selected purposively from two type of industries-70 from a garments industry and another 60 from the tannery industry.

\subsection{Measuring Instrument}

The measuring instruments used were:

1. Demographic and Personal Information Questionnaire: A demographic and personal information questionnaire was used to collect personal and demographic information of the participants, like residence, age, educational status, monthly income, types of the working industry, etc.

2. The Scale of Occupational Stress (Wadsworth and Peters, 2000): A scale of occupational stress was used in this study what was originally developed to measure the stress of the workers and employees with the reflection of some stress creating factors, which are known as working hazards. It was developed by Smith A., Johal S. and Wadsworth E. of Department of Experimental Psychology, University of Bristol and Smith D. George and Peters T. of Department of Social Medicine, University of Bristol. In order to use this scale it was adapted in Bangla by the author herself. This scale contains 13 hazards, like hours of work, physical agents at work, consistency \& clarity at work, job satisfaction, job involvement, attitude to job, support at work, etc which are responsible for creating occupational stress in the workers and employees as a whole. It's a Likert type scale. In this scale among the 13 hazards, 7 are in 4point response format with (often, sometimes, seldom, almost never), 1 is 4-point response format with (very satisfied, satisfied. dissatisfied, very dissatisfied), another 1 is 4-point with (agree, some- what agree, somewhat disagree, disagree), 2 are 2point response format with (yes, no), 1 is 5 -point response format with (not at all worried, mildly worried, moderately worried, very worried, extremely worried) and last 1 is 3-point response format with ( not at all, to some extent and a great deal). Though some of the items are different in case of response format but all are scoring from extremely better to worse (4-1). Just for the two point response format the scoring is $1=$ Yes and $0=$ No and for three point response format the scoring is 1-3. Here by the scoring it is possible to get the individual score for the 13 hazard creating factors as well as it is also possible to get the total score for occupational stress as a whole. The scale is highly reliable: test-retest correlations are typically in the range of .82-.88 for main English version. On the other hand for the Bengali version the test-retest reliability is .79-.81(Akhter, 2008). Even the face validity of the scale is ensured by the judges. Significant correlation of English and Bengali version $(\mathrm{r}=.79, \mathrm{p}<.005)$ indicated translation reliability of Bengali version of this scale.

\subsection{Procedures}

Before applying the final scale of occupational stress a pre-test was conducted on a small sample to find out the acceptance of this scale. It was done about 5 weeks earlier of final application of the final scale. To collect the hazardous factors the subjects were asked a 1-item question during the time of pre-test and told them to say about 3factors which are seriously harmful for their physical and mental health in the working condition and created the job dissatisfaction as well. Here when they told about these 3-factors then those were recorded on the basis of severity i.e. worst affected factor was in first, then the second and then the mild one. After completion of collection of data about this kind then a percentage rate was calculated of these hazardous factors on the basis of response rate of the subjects. In that response sheet some factors were found as same in both field-garments and tannery, such as payment, working time, workload, work overtime etc though the percentage rates are different in the two cases. Finally this self revised Bengali questionnaire was administrated to collect primary data related with occupational stress considering the objectives of the study. The respondents were personally questioned and the questionnaires were filled in by the interviewer based on the response of the respondents. In the time of completion there was no time limit for answering. Autobiographies of the subjects were taken at first by a different page. After the data have been collected, the subjects were bid adieu with thanks and gratefulness. Here they were also requested not to discuss anything with others and were asked to give the related information from their working conditions to make the information reliable. In this way the total procedure was successfully completed. 


\section{RESULTS}

In order to find out the effect of working hazards as the indicator of occupation stress among the workers of two industries-tannery and garments, the collecting data are analyzed by the "Independent Sample t-test". The mean and standard deviation of occupational stress are given in the following Table-2 and Table-3(Appendix).

Table-2: Overall Mean and standard deviation of Occupational Stress between the Garments and Tannery Workers.

\begin{tabular}{|c|c|c|c|c|l|l|}
\hline Groups & \multicolumn{1}{|c|}{$\mathrm{N}$} & \multicolumn{1}{|c|}{ Mean } & SD & t-value & \multicolumn{1}{c|}{ df } & Sig.(2-tailed) \\
\hline Garments & 70 & 172.69 & 13.69 & \multirow{2}{*}{0.35} & \multirow{2}{*}{128} & \multirow{2}{*}{0.728} \\
\cline { 1 - 4 } Tannery & 60 & 171.73 & 16.92 & & & \\
\hline
\end{tabular}

From this Table- 2 it is revealed that there is no significant difference in the mean of occupational stress among the workers of garments and tannery.

Table-3 (Appendix) reveals different occupational stress indicators has some significant effect among the garments and tannery workers but it varies in case of some specific occupational stress indicators; these are - hours of work $(\mathrm{t}=-4.077, \mathrm{df}=128$;

$\mathrm{p}>.05)$, physical agents at work $(\mathrm{t}=-12.330$,

$\mathrm{df}=128 ; \mathrm{p}>.05)$, characteristics of job

$(\mathrm{t}=3.309, \mathrm{df}=128 ; \mathrm{p}>.05)$, support at work

$(\mathrm{t}=-2.662, \mathrm{df}=128 ; \mathrm{p}>.05)$, job satisfaction

$(\mathrm{t}=3.401, \mathrm{df}=128 ; \mathrm{p}>.05)$, attitudes to work

$(\mathrm{t}=4.415, \mathrm{df}=128 ; \mathrm{p}>.05)$ and family work interface $(\mathrm{t}=$ $4.234, \mathrm{df}=128 ; \mathrm{p}>.05)$.

Table-4 (Appendix) highlights the percentage of severity of different hazardous factors those were identified by interviewing the industrial workers of tannery and garment and the justification of their saying was confirmed under the explanation of "The Bangladesh Labor Code, 2006 (3rd rev. ed. Published in 2007, CCB Foundation, Dhaka)". Even it is also found that many hazardous factors are present in both industries though the percentage of severity to predict stress is not same.

\section{Discussions}

From the collected result (Table-2) as there was an unmentionable difference in the mean of the overall occupational stress in respect of the industries-tannery and garments that is because of the differential industrial nature of tannery and garments but the effects of some indicators to create occupational stress differ very significantly in the respect of industries, these indicators are hours of work, physical agents at work, characteristics of job, support at work, job satisfaction, attitudes to work and family work interface. Such result was supported by the previous findings of a study that was about the work environment in different tannery industries of Bangladesh (Doeh-nipsom, 2004). Such study found the ventilation was inadequate in $60 \%$ of the tannery industries in respect to have windows, fan and exhaust fan. But to remove dust from the work environment only in $20 \%$ of industries, the exhaust fans were working well. It is the burning issue for the workers of tannery and garments. Because during the time of working for the absence of ventilation the workers must feel exhaust what make them ultimately very dissatisfied about their work environment, such ventilation is included in terms of physical agents at work. Collected data of the present study revealed a number of hazardous factors which are working as indicators of stress according to the workers in both industrial working conditions and these hazardous factors are categorized under 13 in the original scale which is presented in Table- 3 .

Beside of it, as characteristics of job and support at work make a feeling of independent to the workers so these are also another crucial indicator of occupational stress what varied significantly in tannery and garment. PaulMajumdar (1996) conducted a study in New Delhi, India on women worker in the safety and health context, there they found that as the characteristics of job was different in different job pattern so the rate of being responsive to stress was also varied from work-environment to environment but the influence of these factors to create distress was very remarkable. In this relation, support at work also varied significantly among the workers of tannery and industries. It was supported by a study conducted for the Disability and AIDS Co-ordination Unit, Action Aid Bangladesh, Dhaka on the female workers of garments.

Such kind of supportive findings were also found for the indicator of job satisfaction (Cooper et al. 1997). Even the significant difference for the result of family work interface was also supported by a study of Bangladesh Institute of Development Studies (BIDS, 1997).

From the list of indicators (Appendix, Table-4) it is found that there are some common hazardous factors in both of tannery and garments but in case of severity to determine occupational stress the percentage was not same to all of them. The reason of such specific difference is that in case of garments, workers are not familiar with the threatening chemical materials, irritating sounds which are very harmful for health directly (Steffy et al. 1988) so the workers didn't react directly to such kind of hazardous factors but the workers of tannery reacted severely to such indicators because they are always in a continuous contact with such alarming factors. Nusrat (1998) revealed that in case of tannery the workers were very dissatisfied about their working environment, about the hygiene of the work-room, bad smell of surrounding etc and the present percentage of response is gone with this finding what supports the result of the present study.

Past research by Kornhauser (1965) indicated that poor mental health is directly related with occupational stress. Occupational stress can give rise to job dissatisfaction, increase physical problems, and create lower self-esteem. Occupational stress is not characteristics of either environmental or individual but is the outcome of the interaction of the two. By recognizing the symptoms, identifying the sources of stress and setting specific goals to eliminates or relieve sources of stress can be great help to the industrialists for reducing the stress and the negative 
aspect from the job, working condition. To reduce the effect of hazardous factors the Organizational Safety and Health $(\mathrm{OSH})$ management should be encouraged in garments and tannery industries of Bangladesh by rapid assessment and re-addressing of legislations in industries of Bangladesh. With this, steps in ratifying OSH related International Labor Organization (ILO) conventions should be maintained and formal training program need to organize for all categories of workers for proper use of the safety equipments. As well as to incorporate the workplace environment, standard biological monitoring and formative medical examination scheme need to structured in the tanneries and garments sectors. The authority need to consider the importance of the real life demand during the time of providing and maintaining the salary standard to the workers with the work load and hours of work. Sometimes the management should be arranged some counseling program for both of the workers and the supervisors to reduce the rate of occupational stress.

For the reason of time limitation as it was not possible to investigate the implementation of organizational safety guard tools according to the Bangladesh Labor Code, 2006 so it is the limitation of this study what can recover by a further research. Because in future, such further study has the chance to determine the source which are actually operating in our industrial area as the creator of hazardous factors.

\section{REFERENCES}

[1] Amin, S. (1997).Transition to Adulthood for Working Girls: The case of Bangladesh Garment workers. BIDS Dhaka.

[2] Afsar, Rita.(1995).Rural-Urban Migration and its Impact on Women's Role and Status. Empowerment, a Journal of Women for Women, Vol. 2, 1995.

[3] Anker, R., and Hein, C. (1985).Employment of Women outside Agriculture in Third World Countries: An Overview of Occupational Statistics. World Employment Research, ILO,Geneva.

[4] Bhattacharya, Debapriya. (1997).Women and Industrial Employment in Bangladesh: Challenges and Opportunities in the Era of New Technologies. A Research Report, Bangladesh Institute of Development Studies (BIDS).

[5] Bowler, R.M. et al. (1992) Stability of psychological impairment: twoyear follow-up of former microelectronics workers' affective and personality disturbance. Women and health, 18(3):27-48.

[6] Brisson C, Vézina M, Vinet A. (1992) Health problems of women employed in jobs involving psychological and ergonomic stressors: the case of garment workers in Quebec. Women and health, 18(3):49-65.

[7] BUP. (1990). "A Study on Female Garment Workers in Bangladesh." Bangladesh Unnyan Parishad (BUP), Dhaka, Bangladesh.

[8] Claeson, C. F. (1968). “Distance and Human Interaction” George Ann. B, no. 50, pp.142-161, Scandinavian University Press, Norway.

[9] Eisenbrey, R. and Bernstein, J. (2003). Eliminating the right to overtime pay. Briefing paper. Washington, DC; Economic Policy Institute.

[10] Kanungo, R.n. (1982). Measurement of job and work involvement. Journal of Applied Psychology, Vol. 66667, 341-449.

[11] Komhouser, A. (1965). Mental health of industrial workers, New York
Wiley.

[12] Landsbergis, P.A. (2003). The Changing Organization of Work and the Safety and Health of Working People: A Commentary. Journal of Occupational and Environmental Medicine, 38, 1007-1011.

[13] Mahmood, R. Awal, A. and Paul-Majumder, Pratima. (1996) “Gender and Export-oriented Industrialization: A Case Study of Bangladesh".

[14] Protecting Workers in Hot Environments. OSHA Fact Sheet 95-16, (1995).Available http://www.osha.gov/st.TC/heatstress/recognition.html

[15] Smith, M. J., Carayon, P., Sanders, K.J., Lim, S-Y, and LeGrande, D. (1990). Employee Stress and Health Complaints in Jobs with and without Electronic Performance Monitoring, Department of Industrial Engineering, University of Wisconsin, Madison, Wisconsin and Communications Workers of America, Washington, DC.

[16] Spurgeon, A., Harrington, J.M., and Cooper, C.L. (1997). Health and Safety Problems Associated with Long Working Hours: A Review of the Current Position. Occupational and Environmental Medicine, 54, 367375.

[17] The Bangladesh Labour Code, 2006: 3rd rev. ed. Translated English Version Bangladesh; Publisher: CCB Foundation, Dhaka; Publication Date: 2007. Bindi

[18] Toohey, J. (1997) The Management of Occupational Stress in Commonwealth Agencies, Booklet no, 8 .

[19] Wage and Hour Division, Department of Labor. (1938). Fair Labor Standards Act.Washington, DC. Wage and Hour Division, Department of Labor.

[20] Willquist, P. and Törner, M (2003). Working and Living Conditions of the Garment Factory Workers in Bangladesh and Health Hazards with Special Focus on the Threat of STD/AIDS/HIV. International Journal of Industrial Ergonomics, Vol. 32, Issue 3, 165-180. 